Témoigner

Getuigen
Témoigner. Entre histoire et mémoire

Revue pluridisciplinaire de la Fondation Auschwitz

$118 \mid 2014$

Au nom des victimes. Dictature et terreur d'État en Argentine, Chili et Uruguay

\title{
Onschuldige slachtoffers of militante helden?
}

De herinneringspolitiek en het moeilijke debat over de slachtoffers

Entre innocence et héroïsme. Politiques mémorielles et tensions liées à la qualification des victimes

Between the innocence and the heroism: tensions in the victim's qualification in the politics of memory

\section{Luciana Messina}

Traducteur : Antonia García Castro

\section{(2) OpenEdition}

\section{Journals}

\section{Édition électronique}

URL : http://journals.openedition.org/temoigner/1106

DOI : 10.4000/temoigner.1106

ISSN : 2506-6390

Éditeur :

Éditions du Centre d'études et de documentation Mémoire d'Auschwitz, Éditions Kimé

Édition imprimée

Date de publication : 1 octobre 2014

Pagination : 120-126

ISBN : 978-2-84174-674-3

ISSN : 2031-4183

Référence électronique

Luciana Messina, « Onschuldige slachtoffers of militante helden? », Témoigner. Entre histoire et mémoire [Online], 118 | 2014, Online op 01 octobre 2015, geraadpleegd op 23 octobre 2020. URL : http:// journals.openedition.org/temoigner/1106; DOI : https://doi.org/10.4000/temoigner.1106 


\section{ARGENTINIË}

\section{Onschuldige slachtoffers of militante helden?}

De herinneringspolitiek en het moeilijke debat over de slachtoffers

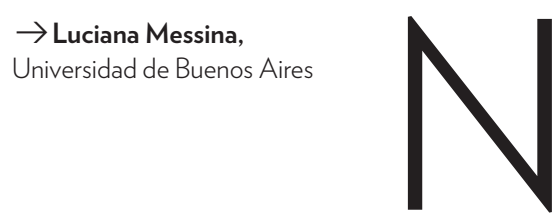

aar aanleiding van de oprichting van memorialen rond de Argentijnse staatsterreur is de laatste jaren een debat ontstaan over de invulling van de term slachtoffer. De drijvende krachten achter de 'herinneringspolitiek'1 in het land zijn hoofdzakelijk mensenrechtenorganisaties, overlevenden ${ }^{2}$ en naar herinnering, waarheid en rechtvaardigheid kon echter niet altijd rekenen op politieke wil en vond soms geen gehoor bij de regeringsvertegenwoordigers in het wisselende politieke landschap de voorbije dertig jaar.

Sinds 2000 hebben verschillende maatschappelijke actoren projecten opgezet (1) Voor meer duiding bij
deze term in het kader van Zuidkegel verwijzen we naar Nora Rabotnikov, 'Memoria y politica
atreinta años del golpe' in Clara a treinta años del golpé, in Clara
E. Lida, Horacio Crespo \& Pablo Yankelevich (red.), Argentina,
1976. Estudios en torno al golpe 1976. Estudios en torno al golpe de
Estado México DF: Centro de Estudios Históricos del Colegio Entre dos muertes. Escansioss
ysilencios en las primers y silencios en las primeras
narraciones historiograficicas acerca del 16 de junio de 1955 2012, 7, http:///wwwufpelpe.edu.br/ ich/memoriaemrede/beta-02-01/
index.php/memoriaemrede/ index.php/memoriaemrede/
article/view/121(geraadpleegd 25

(2) We gebruiken de term in
zijn meest gangbare betekenis. het gaat hier over personen verschillende repressietroepen onder de dictaturuur en die de
gebeurtenissen overleefden; in gebeurtenissen overleefden; in
het bijzonder denken we aan diegenen die in de clandas
gevangenissen werden om plaatsen te valoriseren die materieel of symbolisch verbonden zijn met de politieke repressie en het staatsgeweld. Om het verleden bespreekbaar te maken en er betekenis aan te geven, ging men onder andere over tot de constructie van diverse gedenkplaatsen. Een aantal van deze memorialen kom je automatisch tegen op de openbare weg; naar andere moet je actief op zoek gaan, wil je ze bezoeken. Sommige gedenkplaatsen kwamen er dankzij actievoerders, terwijl andere dan wee het resultaat zijn van grootschalige openbare werken (grootschalig op het vlak van person butgeten dosier (a) van gevangeniscentrum tot mem Innering 'gerecupereerd'

In wat volgt trachten we een antwoord te formuleren op de volgende vragen: hoe krijgt de figuur van het slachtoffer vorm op de gedenkplaatsen in Buenos Aires? Hoe worden de slachtoffers getypeerd, welke identiteit krijgen zij, en wat is het belang daarvan tijdens debatten en discussies? We analyseren met name een aantal evenementen uit het programma van de voormalige clandestiene Olimpogevangenis. ${ }^{3} \mathrm{De}$ betrokken maatschappelijke actoren zorgden voor aanpassingen aan de gebouwen, maar zetten ook een groot aantal activiteiten op touw voor de gemeenschap ${ }^{4} \mathrm{We}$ concentreren on in hetbijzonderopeen evenement dat de tegenstllingen an lichtbrachttussencin Deactiendas.

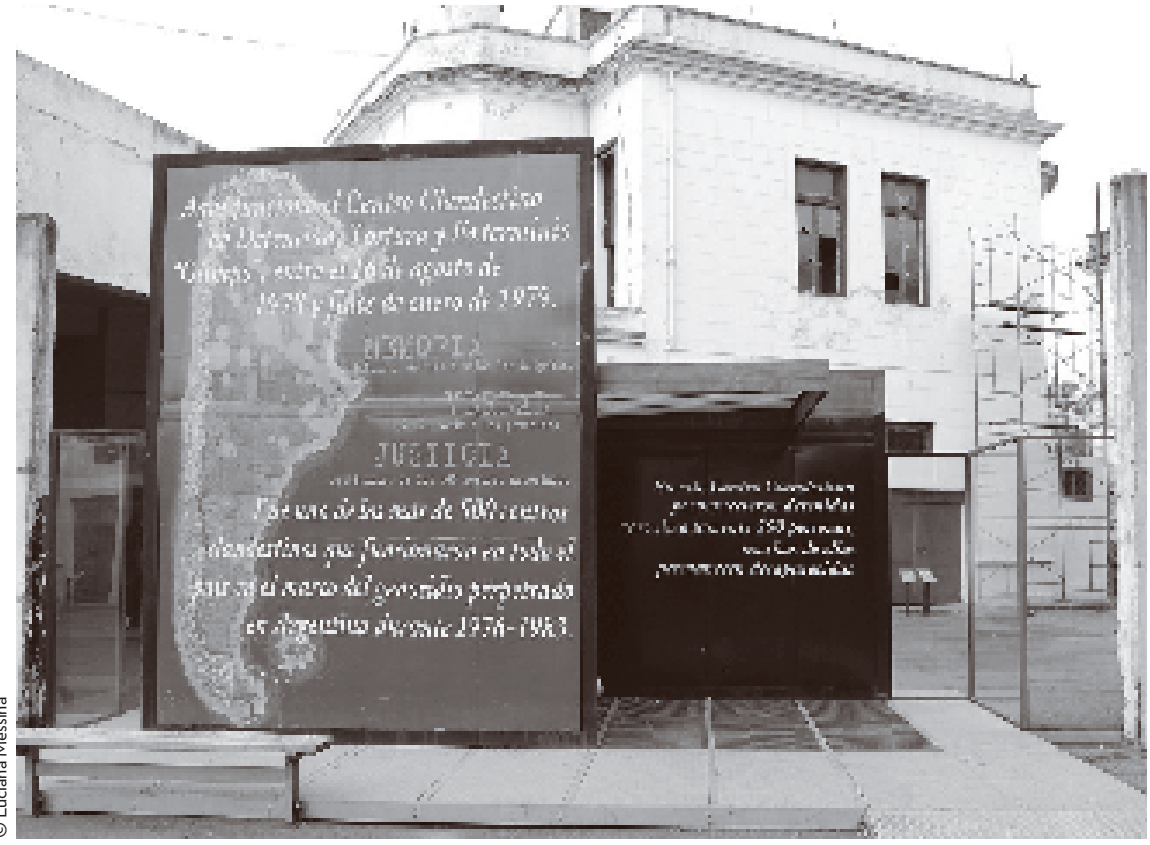

het statuut van slachtoffer en de slachtofferrol. Met de eerste term wordt bedoeld dat de persoon in kwestie geviseerd werd bij een misdaad, een aanval, een vorm van misbruik; de tweede is subjectief en verwijst naar de relatie die deze persoon heeft met zijn of haar verleden. Het statuut van slachtoffer valt dus niet te herleiden tot de subjectieve slachtofferrol, waarbij de gebeurtenis geen herstel vindt maar doorleeft, en het heden gaat domineren.

\section{BURGERHERINNERING VS. MILITANTENHERINNERING}

Het herinneringsbeleid in Argentinië is gebouwd op nalatenschappen, levensverhalen en politieke discours, en in het bijzonder op ervaringen en verhalen van militanten. Het is niet verwonderlijk dat het één groot spanningsveld is. Ook over het statuut van de slachtoffers bestaat geen eensgezindheid, omwille van de diverse 'politieke herinneringsparadigma's's in het land. We moeten de actuele herdenkingsprojecten en -programma's dan ook telkens tegen het licht houden van die verschillende paradigma’s, die sterk afhankelijk zijn van de politieke context van het ogenblik.

We onderscheiden twee periodes. De eerste valt aanvankelijk samen met de democratische overgang (1983-1987) en loopt dan door tot midden jaren negentig. De belangrijkste 'operatoren' of 'betekenisgevers' (Foucault) vinden we terug in De belangrijkste 'operatoren' of 'betekenisgevers' (Foucault) vinden we terug in
het rapport Nunca Más ${ }^{6}$ en in het proces van de voormalige commandanten van
- Ingang van de voormalige clandesti gevangeniscentrum 'Olimpo' in Buenos Aire

(3) De clandestiene gevangenis Olimpo bevond zich in een
gebouw van de Federale Politie in Buenos Aires en werd gebruikt
tussen augustus 1978 en januari
1979. Naar schatting werden er in 1979. Naar schatting werden er in
die vijf maanden 500 personen opgesloten; 100 hebben het 'Les polémiques autour de l'ancien centre de détention
clandestine "EI Olimpo" (Buenos
Airess), in Béatrice Fleury \& Jacques Walter (red.), Qualifier des lieux de détention et de de Nancy, 2008, 291-301. (4) VIl. Luciana Messina, 'Le
dispositif mémoriel de lex Olimpo: Réflexions autour des pratiques de marquage territoria
et d'utilisation du lieu', in Béatrice et dutilisation du lieu, in Beatrice
Fleury \& J acques Walter (red.). Qualifier resc sieux de détention
et de massacre 4. Presses et de massacre 4, Presses
universitaires de Nancy, 2011 , 135-152.

(5) Nora Rabotnikof, 'Memoriay
política a treinta años del golpe', poptert 260.

(6) Het rapport Nunca Más verscheen in 1984 na een
grootschalig onderzoek dat grootschalig onderzzeek
de Nationale commissie voor verdwenen personen
(CONADEP) tien maanden voerde om zicht te krijgen op de methoden en het systeem van de 
de militaire junta. Een tweede fase situeren we midden jaren negentig (1995-1996) wanneer in de publieke ruimte verhalen beginnen te circuleren die de aandacht vestigen op de revolutionaire strijd, waarbijg geweld niet werd geschuwd. In welke mate vragen we ons af, heeft de typering van de verdwenen personen en de overlevenden bepaalde mensen uitgesloten uit de slachtoffercategorie?

Tijdens de democratische overgang (1983-1987) was een maatschappelijk aanvaardbare visie op het verleden gangbaar. Het verhaal benoemde de verantwoordelijken, zonder darbij meer verdeeldheid te zaaien in een toen nog instiwoor tutioneel onstabiele democratie. Het bevestigde precies de belangrijke rol van de instellingen en in het bijzonder die van de burger, die het belangrijkste politieke subject zou worden van de nieuwe post-dictatoriale maatschappij. Dat is meteen ook de reden waarom naar deze eerste periode vaak wordt verwezen als die van de burgerherinnering.?

In de jaren tachtig en begin jaren negentig entte de politieke herinnering zich op getuigenissen van overlevenden die de staatsrepressie aan den lijve hadden ondervonden, en met veel zin voor detail het geweld beschreven dat zij hadden moeten ondergaan in de clandestiene gevangenissen. De hoofdrolspelers in dit herinneringswerk werden op een abstacte manier als slachtoffer setypeerd: het gin om burgers wiens fundamentele rechten systematisch waren geschonden door het

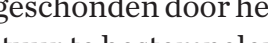
dictatoriale regime. Door de periode voorafgaand aan de dictatuur te bestempelen als een 'gewelddadige tijd', opnieuw in abstracte bewoordingen, werd een radicale breuk gesuggereerd tussen het dictatoriale verleden en het democratische heden. Ondanks het feit dat de dictatuur behoorde tot een vrij recent verleden, werd de afstand met het heden als een diepe kloof ervaren.

Het rapport Nunca Más was een bepalende factor voor de legitimatie en verspreiding van dit verhaal, waarin de feitelijke beschrijving van de misdaden mee aandacht kreeg dan de politieke interpretatie ervan. Het vocabularium dat werd gebruikt om de verdwenen personen te beschrijven behoorde tot het domein van de mensenrechten: het ging over rechtspersonen wiens menselijkheid was aangetast. In het rapport werden de politieke, matschappelijke en economische conflicten In het rapport werden voorafgaand aan de staatsgreep niet historisch gekaderd, omdat het verhaal zich toespitste op de individuele persoon. Op die manier ontstond echter een vereenvoudigde visie op het verleden met een uiterst scherp onderscheid tussen democratie en dictatuur, onschuldige en schuldige slachtoffers. Deze ahistorische kijk op het verleden wekte bovendien het idee dat er tussen de slachtoffers onderling dan wel grote verschillen bestonden qua leeftijd, beroep en sociale afkomst, maar dat ze allemaal het gebruik van geweld afwezen. De term 'verdwenen persoon' is zo synoniem geworden van 'weerloos slachtoffer', iemand die op geen enkele manier betrokken was bij de gewapende strijd van de revolutionairen

Midden jaren negentig ontstond dan een discours dat het militantisme meer in dekijerzete. dekijker zette Nar deze tweedeperiodewordtdon ookvak verwezen als de tijd von de militantenherinnering. Rabotnikof merkt op dat het nieuwe discours een aantal
verschuivingen inhield ten opzichte van sommige kernideeën uit de overgangsver-

(7) VIl Emilio Crenzel, La Buenos Aires: Siglo XXI, 2008 halen. ${ }^{8}$ Zo werden de verdwenen personen meer en meer doelbewust voorgesteld als volksmilitanten ${ }^{9}$ door een groot aantal maatschappelijke actoren op de linkervleugel, en in het bijzonder door mensenrechtenorganisaties. De strijd voor de volkse zaak was in deze periode nog steeds actueel. Er werd daarom teruggegrepen naar de leuzen van de emancipatiestrijd en de nadruk kwam te liggen op de noodzaak van maatschappelijke verandering, eerder dan op de gruwel van de repressie. Het idee van een radicale breuk tussen dictatuur en democratie dat was ontstaan tijdens de overgangsperiode, kwam op losse schroeven te staan.

Het is echter onduidelijk in hoeverre de militantenherinnering wordt gedragen door de bevolking. Het feit dat het verhaal circuleert in de publieke ruimte wijst niet noodzakelijk op het belang ervan voor de maatschappelijke herinnering. Eerder dan een substantiële verschuiving te veroorzaken in de burgerherinnering, lijkt het nieuwe verhaal het oude te duiden en te bevragen op een aantal punten. Het beeld van het 'onschuldige' slachtoffer, los van elk politiek kader, ging aan het wankelen. ${ }^{10}$ Als tegenwicht voor deze historisch foute interpretatie worden nu getuigenissen gevaloriseerd die een rechtstreeks verband leggen tussen het lot van de ontvoerde personen en hun politiek activisme binnen bepaalde organisaties. ${ }^{11}$ Volgens sommige critici heeft het nieuwe verhaal echter geen radicale vragen opgeroepen over de betekenis

Dentinent. ${ }^{2}$

Dan rijst de vrang nar de plates van het slachtoffer in de herinneringspolitiek rond monumenten, memorialen en musea gewijd aan het staatsterrorisme. Welk beeld wordt vandaag gecreeerd van de verdwenen personen en de overlevenden binnen beide herinneringsparadigma's? Waaraan is het eerbetoon precies gericht: aan hun militant verleden of aan hun lijdensweg als slachtoffer? Gaat men uit van een radicale breuk tussen democratie en dictatuur of, integendeel, van een historische continuïteit door vandaag terug te grijpen naar de leuzen en eisen van de revolutionaire strijd? Kortom, geeft de figuur van het slachtoffer aanleiding tot spanningen in het herinneringsveld?

\section{ONSCHULDIGEN OF HELDEN? EEN NON-DEBAT}

Het herinneringsbeleid in de voormalige clandestiene gevangenissen in Buenos Aires veronderstelt een nauwe samenwerking tussen de betrokken openbare instellingen en maatschappelijke verenigingen. Met hun programma richten ze zich bovendien tot de hele samenleving. Sommige activiteiten kunnen we daarom beschouwen als 'analysatoren ${ }^{13}$ die conflicten blootleggen tussen de verschillende verhalen die circuleren over het recente verleden.

We concentreren ons op de vertoning van de film Trelew. La fuga que fue masa$\mathrm{cre}^{14}$, die de controversen, verdeeldheid en twijfels aan het licht bracht over het statuutvan de verdwenen personen en de overlevenden van de statsterreur. Trelew staturt zou een hele reeks van vertoningen en debatten openen binnen het herinneringsprogramma van de oude Olimpogevangenis. Na de vertoning volgde een discussie
(8) Nora Rabotnikof, 'Memoriay (9) In Argentinië verwijst bewegingen en andere politieke organisaties die zich
aansloten bij de revolutionaire idealen van maatschappelijke verandering, over partijgrenzen en ideologische verschilen heen
Ook elders in de tekst gebruiken we de term in deze betekenis.

Raggio in dit nummer gaat dieper (11) Vgl. Pilar Calveiro, Pouvor et disparition. Les camps de
concentration concentration en $A$ inge
La Fabrique, 2006 . (12) Vgl. Hugo Vezzetti,
Sobre la violenciarevolucion Memorias y olvidos, Buenos Aires

(13) Het concept heeft hier
de betekenis die Lourau en apassade eraan geven in hun institutionele analyse. Vil. Uestigación. Métodos, espacios y prácticas profesionales, Buenos
Aires: Eudeba, 2000, p. 35-36. (14) Trelew is een documentaire van filmmaker en antropoloog Mariana Arruti. De film ontsnappingspoging van enkele politieke gevangenen uit de streng beveliligde
Rawsongevangenis (in Patagonië)
en de nasleep van de actie. De gebeurtenissen vonden plaats in augustus 1972 tijdens de militiare
dictaturu $(196 j-1973)$ n sitan geboekstaafd als 'De slachtpartij 
in aanwezigheid van de cineaste zelf en een voormalig politiek gevangene ${ }^{15}$ die in de film wordt geïnterviewd. De discussie beschouw ik in mijn etnografische analyse als een 'microscopisch voorbeeld van grotere conflicten"16.

Het is zaterdag 9 september 2006, 19 uur. We bevinden ons in de gebouwen van de voormalige Olimpogevangenis.

Na de film zitten we met ongeveer dertig personen in de zaal. Een lid van de organisatie geeft de misatie 列 of misluken van het ontsnappingsplan fout werd geïnterpreteerd (de vrouw verwijs naar een scène uit de documentaire waarin men vertelt dat de gevangenen een teken moesten geven aan hun helpers van buitenaf, zodat die konden weten of de operati geslaagd was). De toon van de dame ligt ergens tussen achterdocht en ironie. Het debat gaat verder. Na een tijdje vraagt de dame opnieuw het woord. Ditmaal richt ze zich to de voormalig politiek gevangene. 'Degenen die zijn ontsnapt waren de leiders', zegt ze, en ze vraagt hem of hijzelf en de anderen zich niet 'verraden' voelen door hun aanvoerders. Er valt een stilte. De vrouw zet haar uitspraken kracht bij door toe te voegen dat 'de leiders nog leven’ terwijl de 'onbeduidende militanten' (perejiles) , 'de onschuldigen',

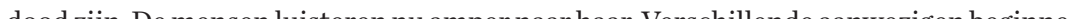
de clijh Demen tegeljk te pate ent het woord en zegt dat 'veel leiders dood zijn, maar gelukkig zijn er ook nog een aantal in leven'. Mensen antwoorden impulsief en roepen door mekaar. De vrouw dringt aan: ze wil nog iets toevoegen, maar de anderen overstemmen haar. Niemand luistert nog naa wat wordt gezegd. Op een gegeven ogenblik komt een man van rond de dertig tussen. Hij zegt dat hij trots is op de militanten van de jaren zeventig, dat hij hen als 'helden' en 'voorbeelden' beschouwt. Zijn generatie heeft geen voeling meer met de waarden die zij hebben uitgedragen en 'kan veel leren van hen, van hun engagement'. Hij spreekt plechtig en is duidelijk ontroerd. Iedereen luistert naar hem. Op het einde vraagt hij aan de 'overlevende' of hij hem de hand mas schudden als eerbetoon aan zijn generatie. De mannen omhelzen elkaar innig. Het debat is ten einde.

Men kan stellen dat het debat is mislukt, of dat er helemaal geen debat heeft plaatsgevonden. Maar wat is er dan precies fout gelopen? In de eerste plaats is er iets onverwachts gebeurd dat de aanwezigen met verstomming heeft geslagen. We hoorden een dissonante stem die een bepaalde 'gêne' heeft veroorzaakt en voor een barst heeft gezorgd in het verhaal van de film en in de gedeelde opvattingen van de meeste mensen in de zaal. Het ongemakkelijke breukmoment ontstond toen de vrouw de verdwenen en vermoorde personen omschreef als 'perejiles' (tweederangsmilitanten), 'onschuldige slachtoffers'. Zo'n omschrijving bleek onaanvaardbaar in deze context. De consternatie was zo groot dat er na de volgende filmvertoning geen debat meer werd gehouden, wat een vij absurde situatie opleverde: doning opleverde: de reeks van films en debatten moest het zonder de debatten stellen. Uit de tussenkomst van
de vrouw en uit de reacties blijkt nog maar eens de kracht van de verhalen die zijn

(16) Vgl. Clifford Geertz, The
Interpretation of Cultures, New

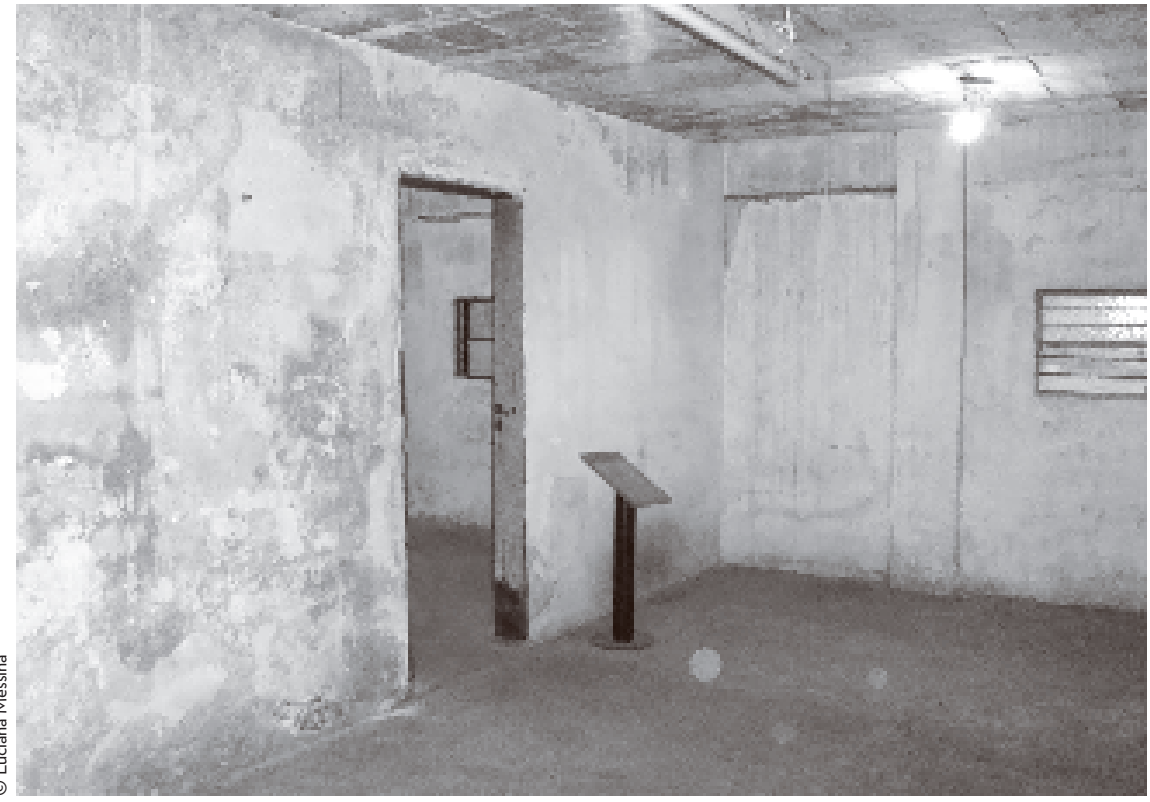

- Binnen in de 'Pozo' in de voormalige

ontstaan tijdens de democratische overgang. De 'burgerherinnering' vormt vandaag de dag voor grote delen van de samenleving nog steeds een valabele interpretatie van de geschiedenis.

Er is nog een andere factor die heeft gemaakt dat er geen echt debat heeft plaatsgevonden, namelijk de tussenkomst van de jongeman en zijn lof voor de heroïsche strijd van de gevangene. Terwijl de vrouw de onschuld van de slachtoffers benadrukte, beweerde de man precies het tegenovergestelde: de militanten waren helden. Zo komen we terugop de slachtofferrol die volgens Rabotnikofeen bijzondere relatie schept tussen politiek en herinning en 'nostalgie nar volheid'veronderstelt. Het verleden vormt een leidraad voor het heden maar wordt in grote mate geïdealiseerd $^{17}$ : wie nostalgisch is naar de volheid van vroeger, rouwt om een verloren paradijs. Het mythische verleden ligt dan nooit helemaal achter ons en is boven elk tijdskader verheven. Het concept van 'nostalgie van de volheid' is een manier om de tussenkomst van de jongeman te begrijpen, en de reacties die zijn woorden losweekten bij het publiek. We merken hoe mensen zich vastklampen aan verloren waarden en hoe ze betreuren dat bepaalde ideeën zijn uitgehold in de loop der jaren.

De jongeman heeft het ongemakkelijke dissonante standpunt van de vrouw overstemd - hoewel zij haar mening te kennen heeft gegeven, werd daar niet werkelijk over gedebatteerd - en bracht weer eenheid in de ruimte. Na de lastige vragen van de oveuw werd de held vrou we to

dan ook een belangrijke kans gemist om in te gaan tegen de heersende opvatting
(17) Rabotnikov heeft het ook nog over, de' melancholie van de
bekeerde' wanneer ze de rol van het verleden in het subjectieve geval is het verleden onderwerp van kritiek of radicale afwijzing. gi. . Nora Rabotnikov, 'Politicic memoria y melancolia', Fract mxfractal.org/sumario29.html 
ARGENTINIË Onschuldige slachtoffers

of militante
(vervolg)

waarbij schuldige slachtoffers (de leiders) worden onderscheiden van onschuldige slachtoffers (de kleine vissen). Deze gedachtegang biedt een moraliserende kijk op de geschiedenis, in plaats van de feiten in hun politieke context te plaatsen.

Tot slot komen we terug op een vraag die Rabotnikof eerder formuleerde, en die tot nadenken stemt omdat ze ook een alternatief inhoudt: kunnen we ons een relatie tussen heden en verleden indenken die 'niet is geworteld in zelfgenoegzaamheid maar toelaat dat het verleden, hoe pijnlijk ook, doorsijpelt in het heden en zo onze vastgeroeste opvattingen bijstelt? Een relatie die de defensieve rol van de nostalgie vastgeroeste opvattingen bijstelt? Een relatie die de defensieve rol van de nostalgie
kan temperen, zonder die volledig uit te schakelen?'18

$$
\text { 怾 }
$$

De scène in de Olimpogevangenis heeft een conflict blootgelegd tussen twee interpretaties van de slachtoffercategorie, de ene verbonden aan de burgerherinnering en de andere aan de militantenherinnering. De verhalen die in de overgangsperiode zijn ontstaan, hebben voor veel mensen nog steeds een reële betekenis en vormen een kader waarbinnen zij de politieke context van toen en de gewelddadige gebeurtenissen kunnen begrijpen. Tijdens het (non-)debat rond Trelew botsten twee herinneringsparadigma's: de ene persoon verdedigde de onschuld van het slachtoffer, terwijl de andere de heldhaftige acties van de militant prees. Beide perspectieven gaan echter voorbij aan het complexe karakter van zowel het revolutionaire miligaan echter voorbij aan het complexe karakter van zowel het revolutionaire mili-
tantisme als het lijden van de slachtoffers onder de repressie. Het nieuwe heldentantisme als het lijden van de slachtoffers onder de repressie. Het nieuwe helden-
dom, maar ook de overdreven focus op de onschuld van de verdwenen personen, zijn twee versies van de subjectieve slachtofferrol waarbij men het verleden gaat idealiseren, en verzuimt kritisch na te denken over de reële implicaties ervan. En laat het nu juist essentieel zijn om de contradicties, ambivalenties en grijze zones in dit verhaal te erkennen. $\mathbf{I}$ 